\title{
Mısır Püskülünün Pamuklu Kumaşlar için Doğal Boyamacılık Özelinde Kullanımının Araştırılması (Mordan Maddesiz Kullanımın, Mordan Maddeli Kullanımla Kıyaslanması)
}

\author{
Investigation of Using Corn Tassel for Cotton Fabrics in Natural Dyeing (Comparison of \\ Use without Mordant with Use with Mordant)
}

Fazlıhan YILMAZ*1,a

${ }^{1}$ Atatürk Üniversitesi, Tekstil ve Moda Tasarımı Bölümü, 25100, Erzurum

\author{
• Geliş tarihi / Received: 09.04.2020 • • Düzeltilerek geliş tarihi / Received in revised form: 18.09 .2020 • Kabul tarihi / Accepted: 30.09 .2020
}

\begin{abstract}
Öz
Yapılan bu çalışmada atıl durumda bulunan mısır püsküllerinin pamuklu kumaşların renklendirilme işlemlerinde kullanılıp kullanılamayacağı araştııılmıştır. Çalışma kapsamında mısır püskülü kullanılarak mordan maddesi olmadan boyama denemesi gerçekleştirilmiştir. Ayrıca buna ek olarak boyama denemelerinde 2 farklı mordan maddesi de (bakır II sülfat ve kalay II klorür) kullanılmıştır. Boyama işlemlerinde flotte oranı 1:50 olarak ayarlanmış ve ögütülmüş olan mısır püskülleri direkt olarak boyama denemelerinde kullanılmıştır. Boyanmış olan pamuklu kumaş numunelerinin yıkama işlemi gerçekleştirildikten hemen sonra kurutma işlemi de yapılmıştır. Kurumuş olan kumaş numunelerinin spektrofotometre yardımı ile renk değerleri ölçümü yapılmıştır. Buna ek olarak bu kumaşların yıkama ve 1şık haslığı testleri de gerçekleştirilmiştir. Yapılan bu işlemler sonucunda pamuklu kumaşların renklendirilmesinde ve bu renkli kumaşların kullanım açısından gerekli haslık değerleri göstermesinde mısır püskülünün kullanılabileceği tespit edilmiştir. Böylece atıl durumda bulunan mısır püsküllerinin farklı bir alanda değerlendirilmesi sağlanmıştır.
\end{abstract}

Anahtar kelimeler: Bakır II Sülfat, Doğal Boya, Kalay II Klorür, Mısır Püskülü, Pamuk, Renk

\begin{abstract}
In this study, it was investigated whether the waste corn tassels can be used in the coloring processes of cotton fabrics. Within the scope of the study, dyeing experiment was carried out without using mordant material, using corn tassel. In addition, 2 different mordant materials (copper II sulfate and tin II chloride) were used in the dyeing experiments. In the dyeing process, the liquor ratio was set to 1:50 and the ground corn tassels were used directly in the dyeing process. Immediately after washing the dyed cotton fabric samples, drying process was also carried out. Color values of dried fabric samples were measured with the help of spectrophotometer. In addition, washing and light fastness tests of these fabrics were carried out. As a result of these processes, it was determined that corn tassel can be used to color the cotton fabrics and to provide the fastness values required for these colored fabrics. Thus, it has been ensured that the waste corn tassels are evaluated in a different area.
\end{abstract}

Keywords: Copper II Sulfate, Natural Dye, Tin II Chloride, Corn Tassel, Cotton, Colour

*a Fazlıhan YILMAZ; fazlihan.yilmaz@ atauni.edu.tr, Tel: (0551) 90794 84, orcid.org/0000-0003-2278-163X 


\section{Giriş}

Tekstil sektörü, hayatımızın her alanında ihtiyaç duyduğumuz ürünleri, çevre şartlarına ve insanların kullanım şekline göre dayanıklı ürünler üretmektedir. Tekstil tarihi ilk insanların örtünmek amaciyla hayvan postlarını kullanmalarıyla başlamıştır. Eski zamanlardan bu yana doğanın renkleri karşısında hayranlığa kapılan insanlar, doğada renkleri her alanda kullanmak istemişlerdir. Güzel görünmek, başkalarını etkilemek gibi nedenlerle doğadan birçok boyarmadde elde edilmiştir. Doğada bulunan renklerin taklit edilmesiyle başlayan doğal boyamacilıkta ilk önce taş, toprak ve maden çeşitleri kullanılmıştır. Daha sonraları ise hayvan ve bitkilerden boyarmaddeler elde edilmeye başlanılmıştır (Akpınarlı ve Tambaş, 2019).

Tarih boyunca süsleme ve renk kavramları farklı amaçlar ve anlamlara hizmet edecek şekilde kullanılmıştır. Kullanılan süslemelerde renk ve teknikler, geçmiş öğretilerden, coğrafi şartlardan ve inançlardan etkilenerek gelişim göstermiştirler. Tarihin her döneminde doğanın vazgeçilmez bir parçası olan insanın ilham kaynağ1, doğada karşılaştıkları ve hissettikleri olmuştur. Doğada bulunan maddeleri kullanarak boyarmadde elde etme, tarihin oldukça eski dönemlerinden beri bilinen bir sanat koludur (Şanlı ve Bak, 2019).

Eski zamanlardan beri renklerin yaşamımızda önemli bir yeri bulunmaktadır. Renkler hayatımızın her alanında belirleyici olmuş, süslemek, süslenmek bazen de iletişim kurmak için ihtiyaç duyulan bir şeye dönüşmektedir. $\mathrm{Bu}$ durum da bizi doğadaki renkleri taklit etmeye kadar götürmüştür. İnsanoğlu bir nesneyi renklendirmek için ise bitkilerin önce çiçeklerinden daha sonra yaprak, meyve gövde ve kök gibi kısımlarından yararlanarak boyarmadde elde etmişlerdir (Şanlı ve Bakır, 2019). Burada da görülmektedir ki doğa, tekstil materyallerinin renklendirilmesi için bizlere birçok kaynak sunmuştur (Ayele vd., 2020).

Tekstil endüstrisinde sentetik ve doğal boyarmaddeler kullanılmaktadır (Dayığlu vd., 2016). Günümüzde sağlık açısından doğal kökenli maddeleri seçmek önemlidir. Bu yüzden kimyasal maddelere karşı bir önyarg1 vardır (Yılmaz vd., 2019). Dünya genelinde kullanılan renklendiricilerin büyük bir kısmını azo boyalar oluşturmaktadır. $\mathrm{Bu}$ bileşiklerin atık sularda bulunması, sucul ekosistemler ve insan sağlığ için toksik etkilere neden olabilmektedir. $\mathrm{Bu}$ sebeple doğal boyarmaddeler tekstil endüstrisinde güvenli bir alternatif oluşturmaktadırlar (Bayraktar ve Tüney Kızılkaya, 2018). Doğal boyarmaddeler çevre dostudur, tehlikesizdir ve sürdürülebilirdir (Amutha vd., 2020). Oldukça geniş bir renk yelpazesine sahip olan doğal boyarmaddeler içerisine katılan mordanlar ile daha da zengin renk tonuna sahip olabilmektedir (Koyuncu Okca, 2017).

Doğal boyarmaddeler tekstil materyallerini renklendirebilir. Bunun yanı sira hem üreticiler hem de tüketiciler açısından bu boyarmaddeler farklı imkanlar ve faydalar sunmaktadır (Bahtiyari and Yilmaz, 2018). Son yillarda doğal boyarmadde elde etmek için, kaynak olarak bitkisel atık kullanımı, farklı araştırmacılar tarafından çalışılmakta olan popüler bir konudur. Söz konusu bitkisel atıkların içeriğindeki renk pigmentleri, buna bağlı olarak da elde edilen renk yelpazesi coğrafi farklılıklara, kullanılan mordanların çeşidine, mordanlama metoduna ve boyanan tekstil lifinin cinsine göre değişiklik göstermektedir (Kayahan vd., 2016).

Ülkemizde bitkisel boyacılık geleneği, geçmişten günümüze kadar süregelmiş bir gelenektir. Doğal boyar bitkiler özelinde dünyanın en zengin bölgelerinden biri olan ülkemizde doğal boyaların önemi oldukça fazladır. Halıdan kumaşa, kumaştan keçeye, keçeden çiniye kadar birçok kültür değerimize renk olan doğal boyalar yüzyıllardır ülkemizde üretilmiştir ve hala üretilmeye devam etmektedir (Şanlı ve Çatalkaya Gök, 2017).

Son zamanlarda özellikle tüketicilerde oluşan çevre bilinci sayesinde doğal boyamacilik tekrardan önem kazanmıştır. Bu sayede üreticiler de tekrardan doğal boyalı ürünler üretmeye başlamışlardır. Yapılan çalışmada, atıl durumda bulunan bitkisel kaynakların tekrardan kullanım alanı bulması için mısır püskülü kullanılarak pamuklu kumaşların renklendirilmesinin araştırılması amaçlanmıştır. Böylece bir bitkisel kaynaktan farklı bir endüstri kolunda faydalanırken bunun atık şeklinde bekleyen bir başka parçasının farklı bir endüstri alanında değerlendirilerek ziyan olmaması sağlanacaktır. Yani böylece ülke ekonomisine yeni bir katma değer oluşturulacaktır.

\section{Materyal ve Metot}

\subsection{Materyal}

Boyama denemelerinde doğal boyarmadde kaynağ1 olarak atıl durumda bulunan misır 
püskülleri kullanılmıştır. Denemelerde kullanılan misır püskülleri herhangi bir ön işlem görmemiştir. Yani boyama işlemi yapılacağı zaman boyama banyosuna direkt olarak eklenmiştir. Bitkisel boyarmadde kaynağı olarak kullanılan mısır püskülüne ait görsel Şekil 1'de sunulmuştur.

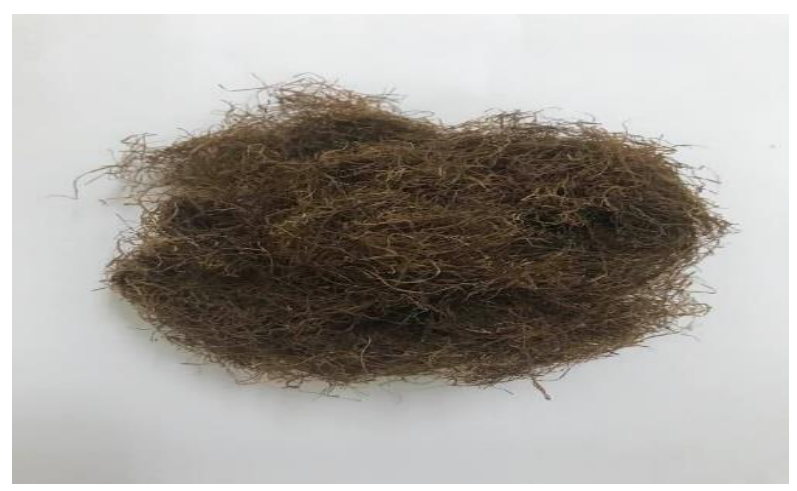

Şekil 1. Kurutulmuş mısır püskülü

Ayrıca yapılan çalışma kapsamında 2 farklı mordan maddesi de kullanılmıştır. Bu mordan maddeleri kalay II klorür ve bakır II sülfattır.

Boyama işlemlerinde kumaş olarak \%100 pamuklu dokuma kumaş kullanılmıştır. Bu kumaşa ait konstrüksiyon özellikleri ise Tablo 1 'de sunulmuştur.

Denemelerde kullanılan pamuklu kumaş numunesi gerekli ön işlemleri gördükten sonra boyama denemelerine hazır hale gelmiş şekilde temin edilmiştir.

Tablo 1. Denemelerde kullanılan kumaşa ait özellikler

\begin{tabular}{llc}
\hline $\begin{array}{l}\text { Gramaj }\left(\mathbf{g} / \mathbf{m}^{2}\right) \\
\text { Elyaf Cinsi }\end{array}$ & & $\begin{array}{c}185 \\
\% 100 \text { pamuk }\end{array}$ \\
Sılklık (tel/cm) & Atkı & 26 \\
& Çözgü & 50 \\
İplik Numarası & Atkı & 20 \\
(Ne) & Çözgü & 30 \\
Örgü Cinsi & & $2 / 1$ Dimi \\
\hline
\end{tabular}

\subsection{Metot}

Yapılan boyama işlemlerine geçilmeden önce pamuklu kumaşlar 2 gram olarak kesilmiştir. Boyama işlemlerinde kumaş/bitki ağırlı̆̆ 1:1 olacak şekilde çalışılmıştır. Yani 2 gr pamuklu kumaş için 2 gr mısır püskülü boyama banyosuna eklenmiştir. Bütün boyama işlemlerinde ise flotte oranı 1:50 olarak ayarlanmıştır.

Boyama denemelerinde mordan maddesi olarak kalay II klorür ve bakır II sülfat mordan maddesinin farkl1 oranları (\%2, \%4 ve \%6) kullanılarak boyama işlemleri gerçekleştirilmiştir.

Bu boyama işlemlerine ek olarak asıl amaç mordan maddesi kullanulmadan bu bitkisel boyarmadde kaynağının pamuklu kumaşlar için renklendirme işlemlerinde kullantlop kullanılmayacağının araştırılmasıdır. İki farklı mordan maddesi yardımıyla yapılan boyama denemelerinde birlikte mordan yöntemi kullanılmıştır. $\mathrm{Bu}$ yöntem sayesinde bitkisel kaynak, kumaş ve mordan maddesi hep birlikte boyama banyosuna eklenerek, boyama işlemleri gerçekleştirilmiştir. $\mathrm{Bu}$ yöntem sayesinde zamandan ve enerjiden kazanç sağlanmıştır.

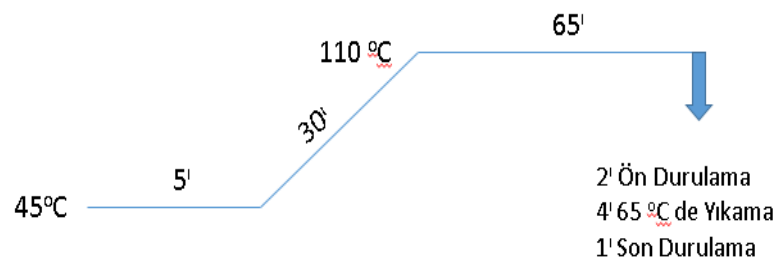

Şekil 2. Mısır püskülü kullanılarak yapılan boyama işlemine ait diyagram

Boyama işlemlerinin hepsi laboratuvar tipi boyama makinesinde gerçekleştirilmiştir. Şekil 2'deki boyama diyagramına göre boyanmış olan kumaş numuneleri oda sıcaklığında kurumaya bırakılmıştır. Kurutma işlemi de tamamlandıktan sonra boyanmış olan pamuklu kumaş numunelerinin haslik testleri (yıkama ISO 105C10standardına göre ve 1ş1k ISO 105-B02 standardına göre) ve renk ölçümleri (CIELAB $\left(L^{*}, a^{*}, b^{*}, C^{*}\right.$ ve $\left.h^{\circ}\right)$ ve K/S (renk verimliliği)) değerleri spektrofotometre yardımıyla ölçülmüştür. Elde edilen sonuçlar ise 3. Bölümde tablola halinde sunulmuştur.

\section{Bulgular ve Tartışma}

Mısırın işlenmesi sırasında atık halde kalan mısır püskülleri ile mordan maddesi kullanılmadan ve 2 farkl 1 mordan maddesinin 3 farkl konsantrasyonunda boyama denemeleri gerçekleştirilmiştir. $\mathrm{Bu}$ denemeler sonucunda mısır püskülleri ile boyanmış olan pamuklu kumaş numunelerinin spektrofotometre yardımıyla renk ölçümleri yapılmıştır. Yapılan bu ölçümlerde elde edilen değerler Tablo 2'de sunulmuştur. 
Tablo 2. Mısır püskülü kullanılarak boyanmış olan yünlü kumaşların renk değerleri

\begin{tabular}{lccccccc}
\hline \multirow{2}{*}{ Mordan Cinsi } & \multirow{2}{*}{ Mordan Konsantrasyonu } & \multicolumn{5}{c}{ CIE L*a*b*(D65) } \\
& & K/S & $\mathbf{L}^{*}$ & $\mathbf{a}^{*}$ & $\mathbf{b}^{*}$ & $\mathbf{C}^{*}$ & $\mathbf{h}^{\mathbf{0}}$ \\
\hline Mordansız & - & & & & & & \\
& $\% 2$ & 0.81 & $\mathbf{7 4 . 8 9}$ & $\mathbf{- 0 . 4 1}$ & $\mathbf{1 2 . 4 7}$ & $\mathbf{1 2 . 4 7}$ & $\mathbf{9 1 . 8 6}$ \\
Kalay II Klorür & $\% 4$ & 0.63 & 81.05 & 0.1 & 14.09 & 14.1 & 89.61 \\
& $\% 6$ & 0.71 & 78.33 & 0.12 & 11.66 & 11.66 & 89.39 \\
& $\% 2$ & 0.81 & 74.98 & 0.16 & 16.04 & 16.04 & 89.42 \\
Bakır II Sülfat & $\% 4$ & 0.82 & 74.56 & 0.52 & 16.28 & 16.29 & 88.18 \\
& $\% 6$ & 0.86 & 73.46 & 0.7 & 15.98 & 15.99 & 87.49 \\
\hline
\end{tabular}

L* açıklık eksenidir. $\mathrm{Bu}$ değer ideal siyahta sıfirdan başlayıp, ideal beyaz için 100'e ulaşır. Yani $L^{*}$ değeri siyah için sıfir, ideal beyaz için 100'dür (Duran, 2008). Tablo 2'de sunulan L* değerleri incelendiğinde en yüksek değerin 81.05 olduğu görülmüştür. En düşük değer ise 73.46 olarak karşımıza çıkmaktadır. En yüksek değere kalay II klorür mordan maddesinin \%4'lük konsantrasyonu kullanılarak yapılan boyama denemesinde ulaşılmıştır. En düşük değerin ise bakır II sülfat mordan maddesinin \%6'l1k boyama konsantrasyonunda elde edildiği gözlemlenmiştir. Mordan maddesi kullanılmadan yapılan boyama denemesi incelendiğinde ise $L$ * değerinin 74.89 olduğu tespit edilmiştir.

$\mathrm{K} / \mathrm{S}$ değeri bilindiği üzere renk verimliliğini ifade etmektedir. Tablo 2'de sunulan K/S değerleri incelendiğinde ise en yüksek değerin 0.86 ile bakır II sülfat mordan maddesinin \%6'lık boyama konsantrasyonunda elde edildiği gözlemlenmiştir. Mordan maddesi kullanılmadan yapulan boyama denemesinde elde edilen $K / S$ değeri ise 0.81 olarak karşımıza çıkmaktadır. Bu değer de elde edilen en yüksek değere yakın bir değerdir. Yani mordan maddesi kullanılmadan da misır püskülï ile boyanmış olan pamuklu kumaş numunesi için genel itibariyle yüksek bir $\mathrm{K} / \mathrm{S}$ değerine ulaşılmıştır. En düşük $\mathrm{K} / \mathrm{S}$ değeri ise 0.57 olarak gözlemlenmiştir. Bu değer ise kalay II klorür mordan maddesinin \%2'lik boyama konsantrasyonunda yapilan boyama denemesinde elde edilmiştir. Mordan maddesi ile yapılan boyama denemelerinde istisnasız olarak mordan maddesi konsantrasyonu arttı̆̆ında $\mathrm{K} / \mathrm{S}$ değerlerinde de bir artış meydana gelmektedir.

\begin{tabular}{|c|c|c|c|c|c|c|}
\hline Mordansiz & $\begin{array}{c}\% 2 \text { Kalay II } \\
\text { Klorür }\end{array}$ & $\begin{array}{c}\% 4 \text { Kalay II } \\
\text { Klorür }\end{array}$ & $\begin{array}{c}\% 6 \text { Kalay II } \\
\text { Klorür }\end{array}$ & $\begin{array}{c}\% 2 \text { Bakır II } \\
\text { Sülfat }\end{array}$ & $\begin{array}{c}\text { \% } 4 \text { Bakır II } \\
\text { Sülfat }\end{array}$ & $\begin{array}{c}\% 6 \text { Bakır II } \\
\text { Sülfat }\end{array}$ \\
\hline sinestive & & 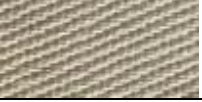 & & & & \\
\hline
\end{tabular}

Şekil 3. Mısır püskülü kullanılarak boyanmış pamuklu kumaşlardan elde edilen renkler

"a*” kırmız1-yeşil eksenini, "b*” sarı-mavi eksenini, "C" doygunluğu ve " $\mathrm{h}$ " " renk cinsini $(\mathrm{h}=$ $0^{\circ}$ Kırmızı, $\mathrm{h}=90^{\circ}$ Sarı, $\mathrm{h}=180^{\circ}$ Yeşil, $\mathrm{h}=270^{\circ}$ Mavi) vermektedir (Duran, 2008). Şekil 3 incelendiğinde mısır püskülü kullanılarak boyanmış olan pamuklu kumaşlarda sarı tonları, bej tonları, kahverengi tonları ve yeşil tonlarının elde edildiği görülmüştür. Örneğin, kalay II klorür mordan maddesinin \%4 'lük konsantrasyonu kullanılarak yapilan boyama denemesinde, $\mathrm{a}^{*}=$ $0.1, b^{*}=14.09$ ve $h^{\circ}=89.61$ olarak bulunmuştur ve renk açık sarı olarak algılanmaktadır. Bir farklı örnekte ise mordan maddesi kullanilmadan boyama işlemi gerçekleş̧tirilmiştir. Bu boyama işleminde, $a^{*}=-0.41, b^{*}=12.47$ ve $h^{o}=$ 91.86'dir. Вu boyama denemesinde ise renk bej olarak algılanmaktadır. Son olarak ise bakır II sülfat mordan maddesinin \%6'l1k konsantrasyonunda yapilan boyama denemesinde ise $a^{*}=0.7, b^{*}=15.98$ ve $h^{\circ}=87.49$ olarak gözlemlenmiştir. Bu boyama işlemi sonucunda ise renk açık yeşil olarak algılanmaktadır. Görüldüğü gibi farklı mordan maddeleri kullanılarak aynı bitkisel boyarmadde kaynağı ile farklı renklerin elde edilebileceği tespit edilmiştir.

Daha önce de bahsedildiği gibi mısır püskülü kullanılarak boyama işlemleri gerçekleştirilen pamuklu kumaş numunelerinin yıkama ve $1 s ̧ 1 \mathrm{k}$ haslığ 1 testleri de yapılmıştır. Elde edilen sonuçlar ise Tablo 3'de sunulmuştur. Tablo 3'deki 1ş1k haslığ1 test sonuçları incelendiğinde en düşük değerin 3-4 olarak elde edildiği gözlemlenmiştir. $\mathrm{Bu}$ değer ise mordan maddesi kullanılmadan ve kalay II klorür mordan maddesinin $\% 2$ ve 4'lük konsantrasyonları kullanılarak yapılan boyama 
işlemlerinde elde edilmiştir. En yüksek değer ise 4-5 olarak gözlemlenmiştir.

Tablo 3. Mısır püskülü kullanılarak boyanmış pamuklu kumaş numunelerinin 1 şık haslığı ve yıkama haslığı test sonuçları

\begin{tabular}{|c|c|c|c|}
\hline \multirow{2}{*}{$\begin{array}{l}\text { Mordan } \\
\text { Maddesi }\end{array}$} & \multirow{2}{*}{$\begin{array}{l}\text { Işık } \\
\text { Haslığg }\end{array}$} & \multicolumn{2}{|c|}{ Yıkama Haslığı } \\
\hline & & $\begin{array}{l}\text { Renk } \\
\text { Değişimi }\end{array}$ & Akma \\
\hline Mordanslz & $3-4$ & 5 & 5 \\
\hline$\% 2 \mathrm{SnCl}_{2} \cdot 2 \mathrm{H}_{2} \mathrm{O}$ & $3-4$ & 5 & 5 \\
\hline$\% 4 \mathrm{SnCl}_{2} .2 \mathrm{H}_{2} \mathrm{O}$ & 4 & 5 & 5 \\
\hline$\% 6 \mathrm{SnCl}_{2} .2 \mathrm{H}_{2} \mathrm{O}$ & 4 & 5 & 5 \\
\hline$\% 2 \mathrm{CuSO}_{4} .5 \mathrm{H}_{2} \mathrm{O}$ & 4 & 5 & 5 \\
\hline$\% 4 \mathrm{CuSO}_{4} .5 \mathrm{H}_{2} \mathrm{O}$ & 4 & 5 & 5 \\
\hline$\% 6 \mathrm{CuSO}_{4} .5 \mathrm{H}_{2} \mathrm{O}$ & $4-5$ & 5 & 5 \\
\hline
\end{tabular}

$\mathrm{Bu}$ değere bakır II sülfat mordan maddesinin $\% 6$ 'lik konsantrasyonunda yapılan boyama denemesinde ulaşılmıştır. Işık haslıkları genel itibariyle incelendiğinde, mordan maddesi konsantrasyonu arttığında ya aynı kalmış ya da artı̧̧ göstermiştir. Mordan maddesi kullanilmadan yaptlan boyama denemesinde elde edilen değer ise mordan maddesi kullanilarak yapılan boyama denemelerindeki sonuçlara oldukça benzerlik göstermektedir. Bu da mordan maddesi kullanilmadan misır püskülleri ile boyanmış olan pamuklu kumaşların kullanım açısından gerekli ışık haslı̆̆ değerlerini nerdeyse mordan maddesi kullanılarak yapılan boyama işlemlerindeki kadar sağladı̆̆ını ifade etmektedir.

Tablo 3'te sunulan yıkama haslığı değerleri incelendiğinde ise hem renk değişimi hem de referans kumaşı kirletme açısından oldukça iyi sonuçların elde edildiği tespit edilmiştir. Yine mordan maddesi kullanilmadan yaptlan boyama denemesinde mordan maddeleri kullanularak yapılan boyama denemelerinde olduğu gibi tatmin edici yıkama haslı̆̆ değerlerine ulaşıldığ tespit edilmiştir.

$\mathrm{Bu}$ sonuçlar neticesinde misır püskülü kullanılarak boyanmış olan pamuklu kumaş numunelerinin kullanım açısından gerekli ve yeterli 1şık ve yıkama haslığ 1 değerlerine sahip olduğu tespit edilmiştir.
Böylece özellikle mordan maddesi kullanılmadan bu bitkisel boyarmadde kaynağının kullanılabilirliği gözlemlenmiştir.

\section{Sonuç}

Ülkemizin birçok bölgesinde mısır yetiştiriciliği yapılmaktadır. Mısırın işlenmesi sırasında püskül kısmı genel olarak atık halde kalmaktadır. İşte yapılan bu çalışmada mısır püskülünün değerlendirilmeden yok olup gitmesinin önlenerek tekstil boyamacılığında kullanılıp kullanılmayacağı araştırılmıştır. Mısır püskülleri kullanılarak mordansız ve 2 farklı mordan maddesinin farkl1 konsantrasyonlarında boyama denemeleri gerçekleştirilmiştir. Gerek mordan maddesi kullanılmadan yapilan boyama denemesinde gerekse mordan maddeleri kullanılarak yapılan boyama denemelerinde misır püskülünün pamuklu kumaşları renklendirebileceği tespit edilmiştir. Bununla birlikte yapılan 1 şık ve yıkama haslığı testleri sonucunda da kullanım açısından mısır püskülü ile boyanmış pamuklu kumaşların gerekli ve yeterli haslık değerlerine sahip olduğu gözlemlenmiştir. Sonuç olarak doğada yok olup gidecek bir bitkisel kaynağın mordan maddesi kullanılmadan bile tekstil boyamacılığından kullanılabileceği tespit edilmiştir.

\section{Kaynaklar}

Amutha, K., Grace Annapoorani, S. ve Sudhapriya, N., 2020. Dyeing of Textiles with Natural Dyes Extracted from Terminalia Arjuna and Thespesia Populnea Fruits. Industrial Crops \& Products, 148, 1-8.

Ayele, M., Tesfaye, T., Alemu, D., Limeneh, M. ve Sithole, B., 2020. Natural Dyeing of Cotton Fabric with Extracts from Mango Tree: A Step Towards Sustainable Dyeing. Sustainable Chemistry and Pharmacy, 17, 1-8.

Akpınarlı, H.F. ve Tambaş, C., 2019. Pamuklu-İpekli Kumaşlara Ekolojik Baskı Uygulaması ve Haslık Düzeylerinin Belirlenmesi. İdil Dergisi, 62, 1295-1311.

Bahtiyari, M.İ. ve Yılmaz, F., 2018. Evaluation of Different Natural Dye Sources in Terms of Metamerism. AATCC Journal of Research, 5(3), 21-27.

Bayraktar, E. ve Tüney Kızılkaya, İ., 2018. Alg Pigmentlerinin Tekstilde Doğal Boyar Madde Olarak Kullanımı. Süleyman Demirel Üniversitesi Fen Bilimleri Enstitüsü Dergisi, 22, 50-57. 
Dayığlu, H., Merdan, N., Eyüpoğlu, S., Kılınç, M. ve Kut, D., 2016. The Effect of Plasma Treatment on the Dyeability of Silk Fabric by Using Phytolacca Decandra L. Natural Dye Extract. Tekstil ve Konfeksiyon, 26(3), 262-269.

Duran, K., 2008. Tekstilde Renk Ölçümü ve Reçete Çıkarma: İzmir, Ege Üniversitesi Tekstil ve Konfeksiyon Araştırma-Uygulama Merkezi Yayın1, 308s.

ISO 105-B02, 1994. Textiles-Tests for Color Fastness - Part B02, Color Fastness to Artifical Light, International Organization for Standardization, Brussels, Belgium.

ISO 105-C10, 2006. Textiles-Tests for Color Fastness - Part C10, Color Fastness to Washing with Soap or Soap and Soda, Test Condition: Test A (1), International Organization for Standardization, Geneva, Switzerland.

Kayahan, E., Karaboyacı, M. ve Dayık, M., 2016. Bitkisel Atıklar Kullanılarak Yün, Pamuk ve Rejenere Soya Lifleri için Ekolojik Boyama. Tekstil ve Mühendis, 23(102), 112-125. 